\section{MEDICAL PARIS OF TO-DAY.}

\section{NOTES MADE IN DECEMBER, 1888.} BY ERNEST HART.

VII.

Hôpital St. Louis: 625 Beds for Dermatological Cases; Outpatient Consultations ; Service of Dr.Vidal; Linear Scarification ; Dr. Besnier; Use of Galvano-cautery; Treatment of Tricophytic Affections; Professor Fournier's Syphilographic Studies; Dr. Hallopeau's and Dr. Quinquaud's Wards ; Thursday Consultations: The Museum and M. Baretta's Casts; the Library; the Ringworm School (Ecole des Teigneux); Hardy's Treatment of the Itch.

IF it is to the Salpetrière that the student of neuropathology-the curious rare forms of hypnotism and hysteria major-and the connoisseurs of diagnostic acumen and highly developed clinical teaching will first direct their steps, it is, on the other hand, to the Hôpital St. Louis, situated in an opposite quarter of Paris, that the devotee of dermatology and the student of syphilography will make his first visit. He finds there a great mass of material, a developed system of examination and teaching, special museums and methods of treatment, many of which have originated on the spot, and are applied with precision and success.

The Hôpital St. Louis is situated on the left bank of St. Martin's Canal, and is now, since the ancient Hôtel Dieu has disappeared, the oldest hospital of Paris. It was founded in 1607 by Henri Quatre, and completed in 1612 under Louis Treize. When built it was outside the walls of the old city, and served for patients suffering from plague who, until then, had been treated, not without peril, at the Hôtel Dieu. The Hôpital St. Louis was thus for two centuries a sort of annexe to the Hôtel Dieu, and under the same administration. Sometimes filled with patients and sometimes completely closed, it was only after the great fire of 1672 , which devoured half the Hôtel Dieu, that it was definitely kept open in order to supplement the requirements of the Hôtel Dieu, which had become insufficient for the purpose. At first it was chiefly occupied by patients suffering from chronic affections not requiring frequent visits, while patients suffering from acute maladies remained in the centre of the city. Thus, at the beginning of this century, the St. Louis contained especially patients suffering from cancer, scrofula, ulcers, lupus, and syphilis. These were the patients whom Alibert and Biett found there when they were charged with the service of this hospital at the commencement of the century. Needless to say what considerable results they drew from their scientific study, and how, gradually, under the impulse of these distinguished physicianssoon followed by Lugol, Cazenave, Devergie, Gibert, Bazin, Hillairet (to speak only of those who are departed), St. Louis became a hospital almost exclusively devoted (so far as its medical wards are concerned) to diseases of the skin and syphilitic diseases.

The actual establishment contains 1,043 beds, of which 625 are reserved for dermatological and syphilographic cases; 242 beds are to be found in the surgical wards, of which I shall speak later on. There is a service of accouchements forming a separate department, and containing 28 beds; and moreover, in a separate barrack, erected in the grounds, provision is made for a temporary service in case of epidemics or special pressure. The engraving, for which I am indebted to Dr. Feulard, the Chef de Clinique of the St. Louis, is taken from his history of the Hôpital St. Louis, published in the Annales de Dermatologie et de Syphiligraphie, 1885. It shows the hospital as it existed in the 17 th century. It has undergone since many changes and extensions, and a careful series of plans of its present installation are given in the current number of The British Journal of Dermatology, in a paper by Mr. Louis Wickham. It will be seen that it is a very picturesque old building covering a great extent of ground supplied with open spaces and courts; and although of ancient construction, the pavilion system on which it is erected, and the free cross ventilation thus afforded, together with the absence of any agglomeration of patients in any one pavilion, supply many of the first requirements of sanitation. The accessory establishments, including the out-patient departments, the baths, arrangements for washing the linen, etc., are on a correspondingly great scale and are well worth administrative study, but I have not here space to do more than indicate their importance. Nor do I desire to dwell on some obvi jus shortcomings. The hydro-therapeutic establishment is very extensive, well mounted and valuable ; indeed, indispensable to so great a collection of patients suffering from skin diseases : its details are of practical interest for therapeutical purposes.

The medical wards are divided under the charge of six physicians, elected by general concours of the hospital physicians of Paris. At the nresent moment they are in the order of seniority, Drs. Vidal, Ernest Besnier, Alfred Fournier, Hallopeau, Quinquaud and Tennesson. Each of these chefs de service controls a series of male and female wards. The number of beds reserved for men is usually greater than those for women. To each physician is attached a house-physician and several clinical clerks and dressers. Each of them has out-patient consultation days, from which his ward beds are filled, and at which on each day from 500 to 600 patients, coming from the outside, are seen and attended to.

The service of Professor Fournier is devoted to the clinique of dermatology and syphilography of the Faculty of Medicine. It therefore possesses also a chef de clinique, who is nominated after concours by the faculty.

1. The service of Dr. Vidal (Membre de l'Académie de Médecine) comprises the wards Alibert (women) and Devergie (men) and the Gabrielle pavilion containing rooms for paying male patients. The outdoor patients of $M$. Vidal come on Tuesday. On the following morning he holds a clinical conference on the cases of the patients who have thus been selected to enter his wards. Thursday he devotes to the surgical treatment of skin affections, such as lupus, chronic acne, keloid, etc. $\mathrm{He}$ is one of the most active promoters of the method of linear scarification in the treatment of lupus, and every week there may be seen in this service numerous patients who come from without to be treated by this method.

2. M. Besnier has two wards situated on the ground floor of the first building on the right and left of the corridor on entering - Gibert ward (women), 32 beds; and Cazenave ward (men), 72 beds. To Cazenave ward is attached a clinical laboratory, in which M. Besnier carries on his teaching, dermatological operations, and out-patient consultations. Dermatological operations are performed on Tuesdays for in-patients and outpatients. After having practised for several years linear scarifications, of which he developed and improved the manual proceeding, $M$. Besnier now usually has recourse to galvano-cautery in virtue of the greater rapidity of action of this method, absence of bleeding, and avoidance of auto-inoculation in lupus, which he considers as being in all cases a condition of local tuberculosis. His out-patient consultation on Wednesdays is devoted to dermatophytic and trichophytic cases, including ringworm, which is very abundant in Paris; favus has become rare there, and is now seen chiefly in patients coming from the provinces or from other parts of the Continent. In the treatment of trichophytic affections of the scalp and beard $M$. Besnier cuts the hair close to the skin with scissors, proscribing the razor, which is apt to cause auto-inoculation. The scalp is thus kept shorn during the whole duration of the disease, which facilitates both treatment and surveillance. The diseased parts are separated from the healthy parts by a zone of epilation carried into the region of the healthy hair. The same general measures are taken for alopecia areata. Favus alone he considers the suitable sphere for practising epilation of the diseased hair; the head is, moreover, kept in the same state as for the preceding affections, and a zone of healthy hair is epilated and is always carefully maintained around the diseased part. These are the general measures; the details of other treatment varying in each particular case. M. Besnier (Membre de l'Académie de Médicine) is one of the directors of the Annales de Dermatologie et Syphiligraphie, and besides other publications he took part in editing and annotating a translation of Kaposi's Lectures on Skin Disease; in the notes the doctrine of the Paris school and the school of Vienna are compared.

3. Professor Fournier represents a part of the official teaching of the faculty-that is to say, he is charged with the clinique of cutaneous and syphilitic disenses of the Faculty of Paris, a chair which was created in 1880 . Every week during the scholastic year Professor Fournier gives two lectures; that on Tuesday is devoted to clinical teaching and presentation of patients ; the Friday lecture is delivered in the amphitheatre constructed at the hospital by the faculty, and treats in professorial fashion of a subject in cutaneous or venereal pathology. A certain number of these lectures are each year reserved for study of some special subject, many being combined in published volumes have become the origin of the works of $M$. 


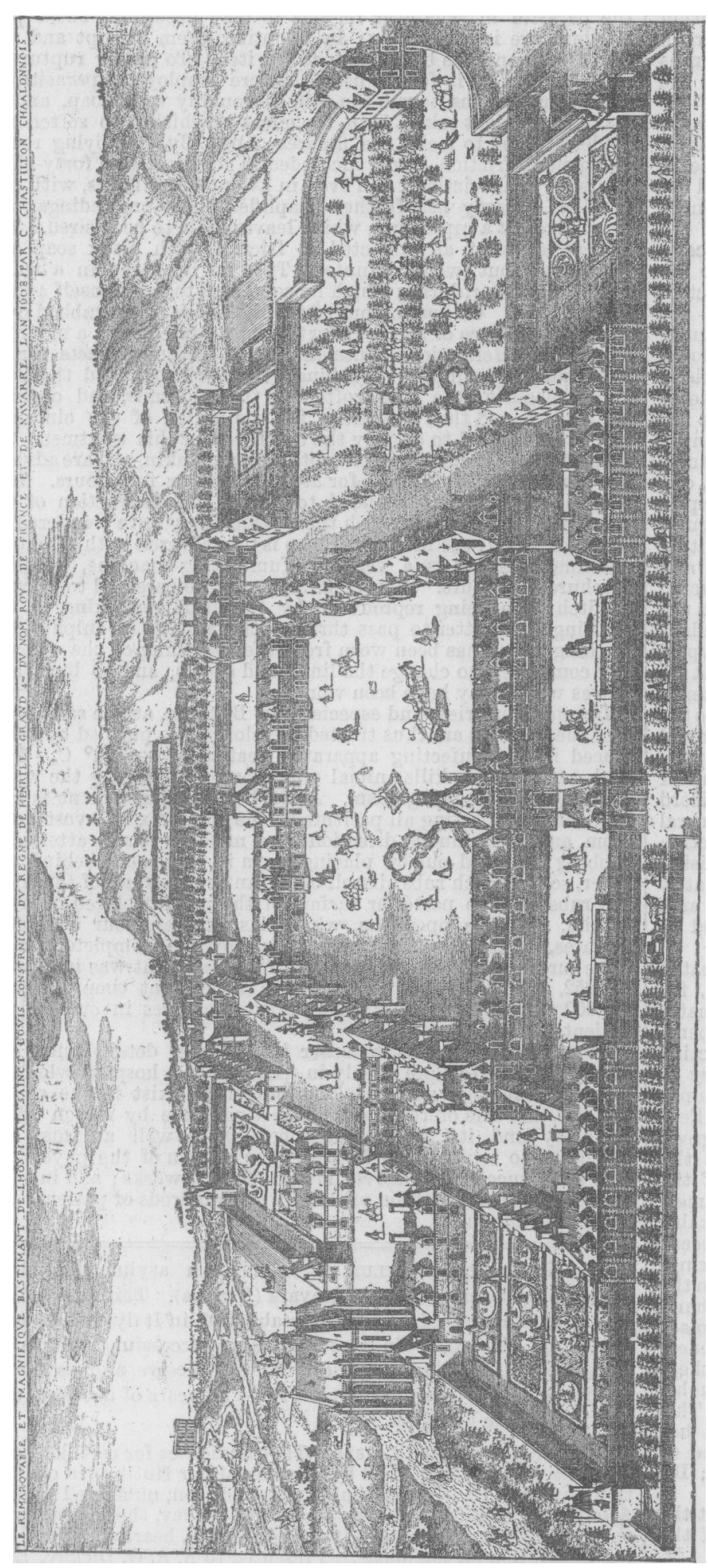

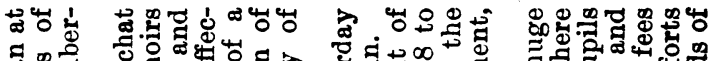

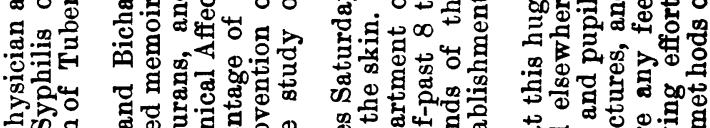

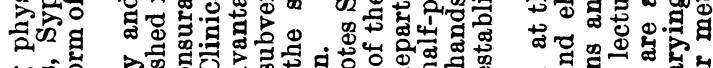
o.p 管出 造荡 .녕

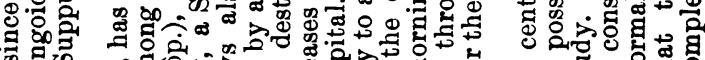

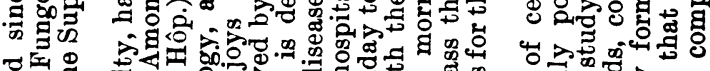
政至

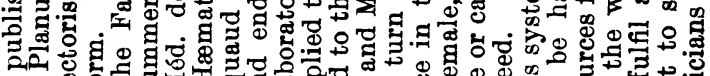
مू 类

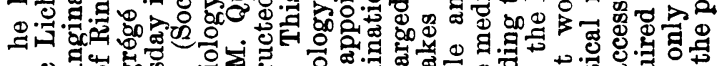

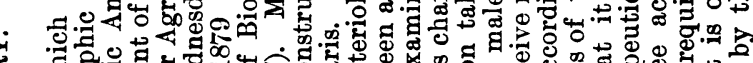

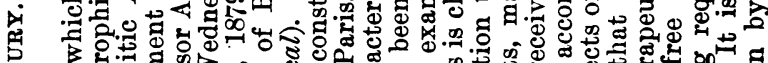
B

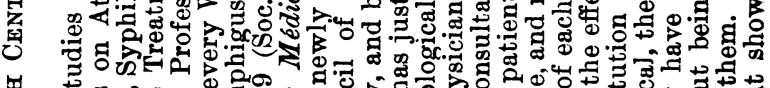

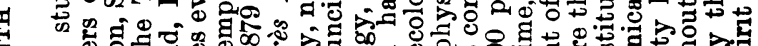

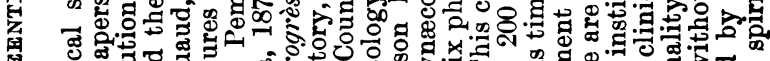

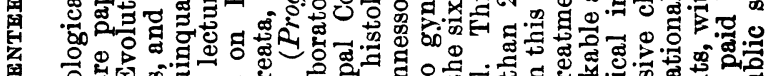

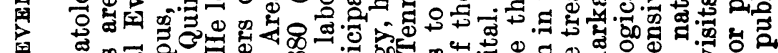

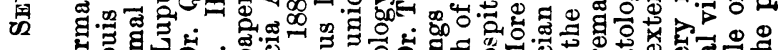

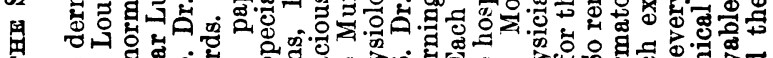

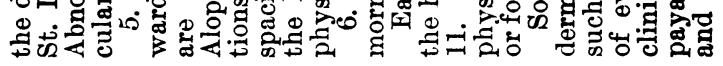

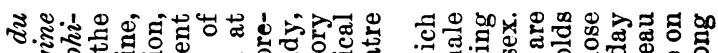
: 政.

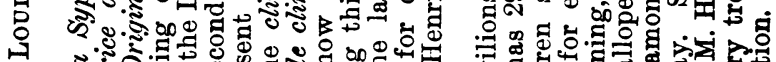
药

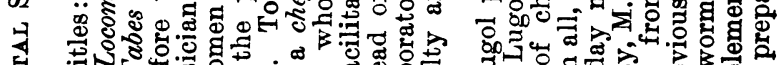
菏4 过 1

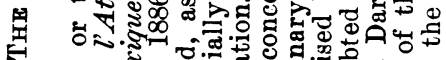
:

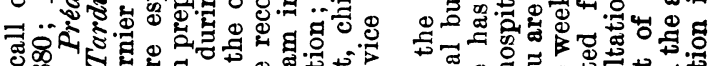

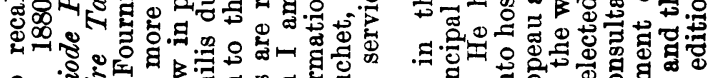

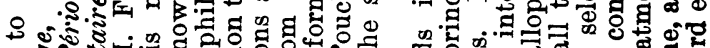

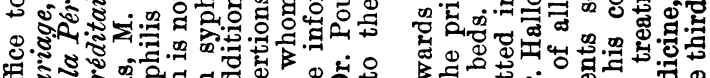
武

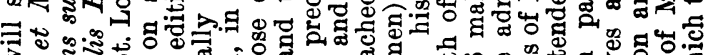

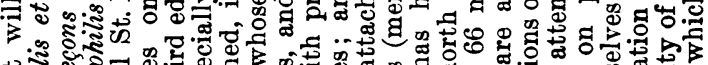

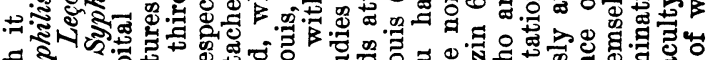

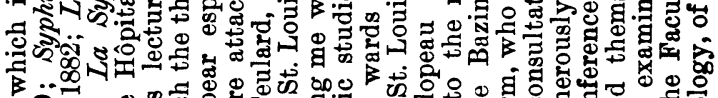

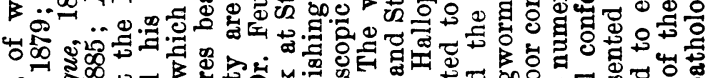

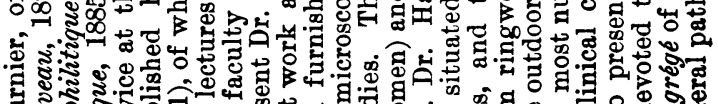
11: 
instruction are not always seconded by the liberality which they have a right to expect from the central authorities.

An excellent institution at St. Louis is the general consultation of Thursday at 9 o'clock, at which all the physicians take part in presenting to each other, and discussing before a numerous auditory in the amphitheatre, the difficult or rare cases of the week, or those which present special elements for study.

St. Louis also contains, as I have indicated, surgical wards under the direction of three surgeons, Drs. Péan, Le Dentu, and J. Lucas-Championnière. Of this surgical service I shall hope to speak in a later letter, in conjunction with other surgical observations; so, also, of the service of accouchment, which is under the direction of Dr. Porak.

One of the leading attractions of this hospital is its celebrated Museum of models of skin-disease, which is to be found on the first floor of a pavilion recently constructed, the ground floor of which is occupied by the rooms for the out-patient consultations. The museum is a large rectangular building, receiving light from the ceiling and from side windows, and filled with cases containing the models. The oldest of these date from the year 1869 . There are now more than 1,400 pieces belonging to the special collection of the hospital, and due to the peculiar talent of $M$. Baretta, who is well known in this country from the number of works which he contributed to the Erasmus Wilson Museum. The " discovery," so to speak, by Dr. Lailler, one of the physicians to the hospital-M. Baretta, who had never previously executed any anatomical models, has attained singular perfection in his work. These models are made of a composition of which the artist keeps the secret. They are very faithful and fresh in colour, and give almost the illusion of Nature, reproducing the most curious cases which have occurred in succession in the wards of the Hôpital St. Louis. This collection furnishes abundant material for clinical teaching and for the study of skin and syphilitic diseases, of which it offers at all times to students the most remarkable types. In this museum, which furnishes a mass of material necessary to illustrate description, will be held from the 5th to the 10th August next the International Congress of Dermatology and Syphilography, which is in course of organisation by the physicians of the hospitals St. Louis, Lourcine, and Midi, and of the faculties of Lyons and Lille, under the presidency of Dr. Ricord and Professor Hardy. Besides 1,400 specimens in the general collection of the museum, it contains, also, the private collection of Professor Fournier, rich in syphilitic types, and comprising more than 400 pieces, modelled by Baretta and Jumelin; that of Professor Parrot, especially concerning infantile syphilis; and, finally, the important surgical collection of Dr. Péan, modelled by Baretta, and including 800 specimens.

To the museum is annexed a library, which has been created during the last year and which already counts 3,000 volumes, for the most part donations. It receives all the journals of dermatology published, and is rapidly becoming a useful and indispensable auxiliary of the museum, by the importance of its collection of books on dermatology and syphilography. This library is placed under the direction of Dr. Henry Feulard, who is occupying himself with preparing a catalogue of the museum. Dr. Felilard is Secretary of the Organising Committee of the Congress, and expects to complete before the meeting of the congress the catalogue of the collections in the museum, and a history of the Hôpital St. Louis, on which he has been working for some time.

This rapid review of the principal services of this remarkable hospital would be incomplete if I were not to mention a recent addition due to Dr. Lailler; a school for children suffering from ringworm. The opportunities at disposal for treating such childrenin the wards and the hospital being insufficient-and on the other hand children suffering from ringworm being excluded from schoolsthe administration of the Assistance Publique of Paris has opened, in some buildings attached to the hospital, a school in which these children are at the same time medically cared for and taught. They come every morning and return home in the evening. This valuable service has been working for two years, and it has proved so useful that the question is now being entertained of establishing another similar school in another part of Paris; Dr. Quinquaud is in charge of it.

I must add also a note of the treatment of itch, instituted at the St. Louis, under the direction of M. Hardy, for this is one of the characteristic features of the place, and has become classic. $M$. Hardy's views as described by himself are that whatever the form of medication chosen for the cure of itch, it is necessary that rough friction should be used in order thoroughly to open the fissures, and to make the parasitic agents reach the acarus, and then it is further necessary to carry out general friction in order to reach the parasite in whatever regions it may occupy. These precautions are indispensable; by adopting them prompt and certain treatment has been obtained for itch. To favour rupture of the channels, it is found useful, before employing parasiticide lotions or frictions, to rub the skin thoroughly with soap, and to make the patient take a bath, the effect of which is to soften the epidermis, and to make the fissures gape. By employing rough and general friction, Bazin succeeded in curing itch in forty-eight hours, by four frictions, and even in twenty-four hours, with two frictions. Hardy has further simplified these proceedings, and has arrived at a rapia cure, which leaves little to be desired. The patient is first of all subjected to friction with black soap and water for about twenty minutes. Then he is placed in a warm bath for an hour, during which he continues to rub himself and to soap himself. On coming out of the bath he is again rubbed ov $r$ the whole surface of the body for twenty minutes, with a modified formula of Helmerich's ointment. This treatment lasts for an hour and forty minutes. Rubbing with black soap and the bath aim at cleansing the skin, softening the epidermis, and opening the fissures, and thus preparing for the action of the ointment which is intended to destroy the acari. After this treatment the patients dress themselves without drying the skin, and are advised not to remove the ointment for at least four or five hours. This prolonged contact is intended to ensure the destruction of the acari, and especially to reach those which may have wandered on to the clothing ; the individual who is thus covered with sulphuroalkaline ointment is a veritable fumigating machine, exhaling sulphurous vapours. Nevertheless, to ensure cure and to prevent the itch from being reproduced by the acari remaining in the clothing, it is better to pass through the vapour of sulphur the clothing which has been worn from the beginning of the disease, and completely to change the linen and sheets, and to burn any gloves which may have been worn.

In some countries, and especially in Belgium, at the same time that the patients are thus treated the clothing is purified by being placed in a disinfecting apparatus heated up to $100^{\circ} \mathrm{C}$. This high temperature kills animal parasites by expanding the water contained in their organism. At St. Louis the treatment is carried out by collecting all patients of the same sex in a vast bathroom, and there, under direction of a male or female attendant, rubbing is carried out by placing them in a line, one behind the other, so that each rubs himself on the anterior surface of the body, and rubs also the posterior surface of the patient placed in front of him. By the operation, which lasts for an hour and forty minutes, the acari and their eggs are destroyed ; to complete thecure some further baths are prescribed. This treatment was instituted in 1852, and it has been applied up to the present time to about 100,000 patients. It gives about fifty-nine cures in every sixty patients.

I cannot allow myself to enter into further details, but I can hardly abbreviate more closely in speaking of a hospital which is assuredly the most extengive of those which exist in the centre of Paris, and one of the most interesting alike by reason of its antiquity and its architectural beauty, as well as from the speciality to which it is devoted; the renown of the physicians who have successively served it and of their works; and in view of the copious instruction offered by its hundreds of patients and its unique museum.

The Frrst Idiot Asyudm in Italy.-An asylum for idiots has recently been opened at Chiavara (Liguria). This institution, which is the first of the kind established in Italy, will be conducted on the same lines as the most successful asylums of the same class in other countries. It will receive, and as far as possible educate, patients between 7 and 20 years of age from any province in the kingdom.

Colne Ambulance Classes.-The candidates for certificates at a recent examination, held by Surgeon-Major Hutton, in connection with the St. John Ambulance Association, numbered eighty. After the distribution of certificates, Dr. Dickey, the instructor of the classes, was presented with a gold watch, bearing the following inscription on the dome: "Presented to A. A. G. Dickey, Esq., M.D., by the male and female members of the Colne Ambulance Classes, police force, and fire brigade, in recognition of his services as lecturer." 


\section{REFORM AT THE ROYAL COLLEGE OF SURGEONS.}

Sir,-We have the honour to enclose copies of an important correspondence that has within the last few days taken place between ourselves, as representing the Association of Members of the Royal College of Surgeons, and the President and Secretary of the College. It will be within the recollection of the readers of the Jounnal, that on January 10th, after considering a letter addressed by one of ourselves to the Secretary of the College, and by order of the Central Committee of the Association, the Council of the College resolved: "That Mr. Ellis be informed that the Council do not think it expedient to convene a meeting for the purpose mentioned in his letter."

The Association, at its last annual meeting (January 31st, 1889), thought otherwise, and consequently resolved to convene the meeting referred to in this correspondence. We do not consider any further comment necessary, but merely add that it is still our intention that the meeting be held on February 28th, at 3 P.M., at the College.-We are, Sir, your obedient servants.
February 21st, 1889.
WARWICK C. STERLE.
Wir. Ashton Ellis.
Honorary
Secretaries.

14, Grosvenor Road, S.W., February 14th, 1889.

Sin,-By direction of the Association of Members of the Royal College of Surgeons of England, we have the honour to submit the enclosed copy of a requisition received by us, and are likewise instructed by the Central Committee of the above-named Association to say that they trust you will place at the disposal of the meeting of the Fellows and Members therein mentioned either the theatre or the lower library of the College at Lincoln's Inn Fields.-We are, Sir, your obedient servants,

$\left.\begin{array}{l}\text { WARWICK C. STEELE, } \\ \text { WM. ASHTON ELLIS, }\end{array}\right\} \begin{aligned} & \text { Honorary } \\ & \text { Secretaries }\end{aligned}$

To the President of the Royal College of Surgeons of England.

[ENCLOSURF.]

The undersigned Members of the Royal College of Surgeons of England being apprised of the refusal of the Council of the said College to convene a meeting of the Members for the purpose of considering the action to be taken pursuant to a letter of the Clerk of Her Majesty's Privy Council dated November 27th, 1888, hereby request the secretaries of the Association of Members of the Royal College of Surgeons to convene a meeting of the whole body of the Members to be held at the College in Lincoln's Inn Fields on Thursday, February 28th, at 3 P.M., for the purpose of considering the situation of the College, and taking such action in Parliament or otherwise as to them shall seem fit, in exercise of the constitutional right of the Members of the said College to meet and take counsel together concerning the affairs thereof; and the undersigned Members further request the said secretaries to give notice of the said meeting to the Members of the College by circular or otherwise, and to intimate the present requisition to the President and Council, and to the Secretary of the said College.

\section{Royal College of Surgeons of England, Lincoln's Inn Fields, London, W.C.,} February 15th, 1889.

Gentuenen,-I am desired by the President to acknowledge the receipt of your letter of the 14th instant, submitting to him, by direction of the Association of Members of the College, an enclosed copy of a requisition received by you, and expressing, on behalf of the Central Committee, a hope that he will place at the disposal of the meeting of Fellows and Members therein mentioned, either the theatre or the lower library of the College, and I am directed to state that the President will submit to the Council of the College at a meeting to be held on Thursday, the 21st instant, such letter and enclosure.

I am at the same time desired to direct your attention to Section $x$ vii of the by-laws, a copy of which I enclose.-I am, Gentlemen, your obedient servant,

Warwick C. Steele, Esq

Edwand Trmmer, Secretary.

Wm. Ashton Ellis, Esq.

Royal College of Surgeons of England, Lincoln's Inn Fields, London, W.C. February 16th, 1889

SIR,-The attention of the President of the College has been called to an advertisement in the Lancet and BRITISH MEDICAI JOURNAL of this date, purporting to be signed by you, and announcing that a meeting of the Fellows and Members of the College will be held at the College on the 28th inst.

I am desired by the President to inquire whether such advertisement was issued by your authority, and to point out to you that any Member issuing such an advertisement is guilty of a breach of Clause 1, Section xvii, of the By-laws of the College, and renders himself liable to the penalties specified in that clause.

Such advertisement will be considered by the Council on the 21 st instant, and I am directed to request that you will inform me by that date whether it was issued by your authority, and, if so, whether you have any explanation which you may desire to give or any reasons to submit to the Council why they should not proceed to enforce the penalties prescribed by the by-law.

I enclose a copy of Section xvii of the By-laws.-I am, Sir, your obedient servant, Edward Trimmer, Secretary.

Warwick C. Steele, Esq.

(A duplicate of this letter was addressed to Mr. Ashton Ellis.)

$$
\text { SeCrion:XVII.-Meetings of Fellows and Members. }
$$

1. No business whatever shall be transacted, nor any matter be discussed or 1. No business whatever shall be transacted, nor any matter be discussed or debated, at any meeting or assemblage convened by or under the authority of menced, other than the particular business or matter in respect of which such meeting or assemblage shall have been convened; nor shall any debate or discussion whatsoever be had or allowed at any meeting convened by the President or Council for the delivery of lectures or orations, either before or after the same shall have been commenced or terminated. And no meeting or assemblage of Fellows or Members of the College shall be held in the Hall or Council House of the College, or in any of its appurtenances, unless convened by or underthe authority of the President or Council ; and no Fellow or Member of the College shall advertise, or convene or attend, or combine with others to advertise, or convene or attend, any meeting or assemblage in the Hall or Council House of the College; or in any of its appurtenances, not authorised by the President or Council. And any Fellow or Member of the College who may in any manner offend herein shall be liable to be restrained and excluded by the Council from attending any orations and lectures at the theatre, and from any use of or admission to the library and museum, and to be suspended from any or all other privileges which he may have as a Fellow and Member or a Member of the College, for any such period have as a Fllow and Member or a Member of the College, for any such period as the Council may adjudge, or to removal by resolution of the Council from being a Fellow and Member or a Member of the College. And every Fellow or forfeit all his rights and privileges as a Fellow and Member or a Member thereof.

2. All meetings convened by or under the authority of the President or 2. All meetings convened by or under the authority of the President or Council of the College, as well for general business as for the delivery of orations or lectures, or for the distribution of prizes, shall be under the control and direction of the President or other member of the Council presiding at
such meeting. And any Fellow or Member of the College who shall interrupt,
impede, or interfere with the proceedings at any such meeting, or shall proimpede, or interfere with the proceedings at any such meeting, or shall propose any matter for discussion or debate without the leave of the President or other person so presiding, shall, upon being required by the President or ther person so presiding, immediately withdraw from such meeting; and shall be moreover liable to be restrained and excluded by the Council from attending any orations and lectures at the theatre, and from any use of or admission to the library and museum, and to be suspended from any or all other privileges which he may have as a Fellow and Member or a Member of the College, for any such period as the Council may adjudge. And any Fellow or Member of the College who shall so offend a second time, or during any suspension by the Council shall attempt to exercise any of the privileges from which he shall be suspended, shall be liable to removal by resolution of the Council from being a Fellow and Member or a Member of the College. And every Fellow or Member of the College who shall thereupon be removed as aforesaid shall forfeit all his rights and privileges as a Fellow and Member or a Member
thereof.

Association of Members of Royal College of Surgeons, February 20th, 1889.

SIR,-We have the honour to acknowledge receipt of your communications of the 15 th and 16 th inst. relating to the proposed meeting of the Fellows and Members of the College on the 28th inst. for the consideration of a Bill to be promoted in Parliament pursuant to the suggestion conveyed to us by Her Majesty's Privy Council.

We regret to learn that the advertisement which appeared by order of the Association of Members of the College in the Lancet and BRITISH MedrCAL JouRnal of the 16th inst. is disapproved by the President, and we desire that it should be at once understood that the whole of the arrangements for the intended meeting, including the advertisements thereof, are designed to maintain what, as the Association is advised and believes, are the ancient and indisputable rights of the College, and are not intended to convey the slightest disrespect or discourtesy to the President and Council. They are based, as you are already aware, not only upon a unanimous resolution of the Association of Members at its last annual meeting, but also upon the formal requisition signed by R, Abud, G. H, Batterbury, E. H, Biddlecombe, M, G. Biggs, G. 
H. Cable, W. Carter, R. Collum, W. G. Dickinson, T. Stretch Dowse, W. A. Elliston, F. H. Forshall, R. Gooding, E. Hartley, R. Hicks, Jabez Hogg, C. M. Jessop, J. D. Macdonald, E. McKellar, J. W. Mason, J. W. B. Mason, R. Purvis, W. D. Smallpeice, J. Smith, J. C. Smith, S. Smith, Lawson Tait, G. Danford Thomas, and W. Wynn Westcott, of which a duplicate is in the hands of the President.

The proceedings have throughout been taken under legal advice, and we believe that the present step was resolved upon by the Association, as being apparently the only course left open to the Members by the action of the Council at its meeting of the 10th ult.

We are aware that the members of the Association sincerely regret the necessity of taking formal steps which do not commend themselves to the President and Council, but we are sure that the President and Council will recognise their desire to conduct in a spirit of justice and moderation the unhappy controversy, which has now continued for many years, concerning the nature of the rights of the Members to intervene in thel consideration of the affairs of their own College.

We ought to say that we are advised that the stringent lpenal clauses of the xviith By-law are not of legal validity nor applicable to the present matter ; if they were, it is apparent that they would also apply to many of the previous acts of the Association of Members in the course of the present discussion.

While we are not therefore able to admit the jurisdiction of the President and Council to take any proceedings against us or the signatories to the requisition under or by authority of the xviith By-law, we beg to say that, if the Council should resolve to proceed in the matter, it would be our desire to submit to them, under protest, a full explanation of the reasons which, to us personally, justify the steps we have felt it our duty to take, and that for this purpose we claim to be heard by counsel.-We are, Sir, your obedient servants,

W. Wu. Ashton Ellis, 14, Grosvenor Road, S.W.

To the Secretary of the Royal College of Surgeons of England.

\section{ROYAL COLLEGE OF SURGEONS.}

As Extraordinary meeting of the Council was held at the College on Thursday, February 21 st, when the minutes of the last meeting were read and confirmed.

A report was read from the Committee appointed to consider the formulæ for the new By-laws granted by the Charter. The repnrt was approved and accepted by the Council, and referred to the Jommittee, as provided by Section iii of the By-laws.

The Presinent moved that the best thanks of the Council be, and are hereby, given to Mr. Henry Power for his Hunterian Oration delivered on the 14th instant, and that he be requested to publish the same. The motion was carried unanimously.

A letter was read, addressed to the President, on February 14th, from Mr. Warwick C. Steele and Mr. William Ashton Ellis, Honorary Secretaries of the Association of Members of the College, submitting, by direction of the Association, a copy of a requisition received by them, and requesting, by the instructions of the Central Committee of the Association, the President to place at the disposal of the meeting of Fellows and Members therein mentioned either the theatre or the lower library of the College.

It was resolved unanimously that Messrs. Steele and Ellis be informed that the Council is unable to grant the request contained in their letter, as the meeting which they ask permission to hold would be illegal, being contrary to the By-laws, and cannot therefore be allowed.

The President reported that his attention had been called to an advertisement which appeared in the Lancet and BRITISH Menical Journal of February 16th, purporting to be signed by Messrs.Warwick Steele and William Ashton Ellis, and announcing that a meeting of Fellows and Members of the College would be held at the College on February 28th, and that he had referred the question to Mr. Wilde for his opinion as to what steps could be taken in the matter.

A draft was read of a letter of February 16th, prepared by $\mathrm{Mr}$. Wilde, and addressed to Mr. Steele and Mr. Ellis, inquiring whether the advertisement purporting to be signed by them was issued by their authority, pointing out to them the breach of Clause 1, Section xvii, of the By-laws, of which they had been guilty, informing them that the advertieement would be brought under the con- sideration of the Council on February 21st, and affording them the opportunity of offering explanations or submitting reasons why the Council should not proceed to enforce the penalties incurred by them under the said Section of the By-laws.

A reply was read from Messrs. Steele and Ellis questioning, under legal advice, the:validity of the By-law, and its applicability to the present matter, not admitting the jurisdiction of the President and Council, and adding that, should the Council determine to proceed under Section xvii of the By-laws, it would be their desire to submit, under protest, a full explanation of the reasons which justify them personally in the steps they have taken, claiming to be heard by counsel.

A resolution was passed that the consideration of the infraction of the By-law by the conveners of the illegal meeting of Fellows and Members be postponed till the next ordinary meeting of the Council on March 14th; and that the Fellows and Members implicated in the matter be desired to give reasons in writing why the Council should not proceed to inflict the legal penalties.

It was resolved unanimously that the College be closed from the evening of Wednesday, the 27 th instant, to the morning of Friday, March 1st, and that a notice to that effect be posted in the College.

The thanks of the Council were conveyed to Messrs. Sibley and Willett for the assistance they had rendered to the medical officers of the Board of Trade in the preparation of the medical scales for passenger ships.

\section{ASSOCIATION INTELLIGENCE,}

\section{NOTICE OF QUARTERLY MEETINGS FOR 1889. ELECTION OF MEMBERS.}

Matingas of the Council will be held on April 17th, July 10th, and October 16th, 1889. Candidates for election by the Council of the Association must send in their forms of application to the General Secretary not later than twenty-one days before each meeting, namely, March 28th, June 20th, and September 26th, 1889.

Any qualified medical practitioner, not disqualified by any bylaw of the Association, who shall be recommended as eligible by any three members, may be elected a member by the Council 0 by any recognised Branch Council.

Candidates seeking election by a Branch Council should apply to the Secretary of the Branch. No member can be elected by a Branch Council unless his name has been inserted in the circular summoning the meeting at which he seeks election.

\section{Francis Fowke, General Secretary.}

\section{BRANCH MEETINGS TO BE HELD.}

Shropshire AND Mid-Wales Branch.-A half-yearly meeting of this Branch will be held at the Salop Infirmary on Tuesday, March 5th, at 3 P.M. Members desirous of reading papers, notes of cases, etc., are requested to communicate with the undersigned, Enward CURETON, Honorary Secretary.

Yorkshire Branch.-A meeting of the members of this Branch will be held in the Town Hall, Bradford, on Wednesday, February 27th, at 3 P.M. Members in the Town Hall, Bradora, on wested to communicate at owce with the Secreintending to read ppaers

StAFFORDSHIRE BraNCH.-The next meeting of this Branch will be held in the Swan Hotel, Stafford, on 'Thursday, February 28th, at 3.45 P.M.-GEORG REID, Honorary Secretary.

WeST SOMERSET BRANCH.-The spring meeting of this Branch will be held at the Railway Hotel, Taunton, on Thursday, March 14th, at 5 P.M. Dinner at 5.30 P.M. The question settled by the Council to be discussed after dinner is. "What is your Experience of the Use of Digitalis and Strophanthus in Heart What is "y our the meeting kindly communicate with W. M. KELLY, Honorary Secretary.

Solth-WeSTERN BRANCH.-An intermediate meeting of this Branch will be held at the Gerston Hotel, Paignton, on Tuesday, March 12th, at 2.30 P.M. Members proposing to read papers, or to show cases, specimens, etc., are requested to intimate the same to the Honorary Secretary. Luncheon will be provided at 1.45 P.M., at 28 . 6त. per head, and members who propose to attend the luncheon are requested to communicate with Dr. Alexander, Paignton, a few days before the meeting. The following papers have been already proraised: Dr. A. G. Blcmfield (Exeter) : Case of Cerebral Syphilis. Mr.J. D. Harris (Exeter) : Case of Pulmonary Cavity Successfully Treated by Drainage, -P. MA URY DEAs, Honorary Secretary, Wonford House, Exeter. 